\title{
COMPARATIVE STUDY OF PLATELET COUNT IN DIABETIC AND NON-DIABETIC GERIATRIC
} POPULATION

\author{
Dr. Ayachit Kesharwani ${ }^{1}$ (PG Resident 2nd Year), Dr. Imran Khan ${ }^{2}$, (PG Resident 3rd Year), Dr. Mohit Awasthi ${ }^{3}$ (PG \\ Resident 2nd Year) \& Dr. Ravija Prasad ${ }^{4}$ (Asst. Prof.)
}

Dept. of General Medicine, Index Medical College Hospital \& Research Centre, Indore, M.P., ${ }^{1,2,34}$

\author{
Article Info: Received 20 November 2021; Accepted 29 December 2021 \\ DOI: https://doi.org/10.32553/ijmbs.v6i1.2387 \\ Corresponding author: Dr. Ravija Prasad \\ Conflict of interest: No conflict of interest.
}

\begin{abstract}
Geriatric population (> 60 years) is rapidly increasing in India, It has been increased upto $8.6 \%$ in 2011. Diabetes Mellitus (DM) is a metabolic disorder and a major health problem, affecting a large section of the Indian population, especially as its incidence increases with advancing age. Host of complications are associated with this disease, one of which is the effect on platelet count. This study compares platelet count between diabetic and non-diabetic elderly. It is observed that Hyperglycaemia in diabetic persons is responsible for increased Thrombopoietin production at the cellular level, which leads to raised platelet count -Reticulated Thrombocytosis - when compared to non diabetics. Platelets, especially reticulated thrombocytes are associated with uncontrolled blood sugar levels in the body and are well known for their role in artherosclerotic cardiovascular disease (CVD).
\end{abstract}

Keywords: platelet count, diabetic and non-diabetic \& geriatric.

\section{Introduction}

Geriatric or elderly age group faces lot of challenges, both physiological and pathological. Aging is the progressive, universal decline first in functional reserve and then in function that occurs in organisms over time. Ageing is universal but proceeds at highly variable rates, with wide heterogeneity in the emergence of the aging phenotype. Homeostatic mechanisms are slower to respond to stressors and take longer normal function. According to 2011 census, the elderly population in India is rapidly growing and stands at $8.6 \%$, compared to $5.6 \%$ in 1961. Apart from the decline in functions which occur as part of the timescale, presence of any chronic disease adds to the morbidity in the elderly. Of the many chronic ailments, Diabetes mellitus is probably the most dreaded as it can affect multiple organ systems of our body.

Diabetes mellitus is a metabolic disorder of multiple aetiology characterized by chronic hyperglycemia with disturbances of carbohydrate, fat and protein metabolism resulting from defects in insulin secretion, insulin action or both. People with diabetes are at increased risk of cardiovascular, peripheral vascular and cerebrovascular diseases.

Diabetes can be classified into Type 1 and Type 2 .

Type 1 Diabetes is due to almost complete deciency of insulin production whereas Type 2 Diabetes Mellitus is a heterogenous group of disorders characterized by variable degrees of insulin resistance, impaired insulin secretion and increased glucose production. Distinct genetic and metabolic defects in insulin action and/or secretion give rise to the common phenotype of hyperglycaemia in type 2 Diabetes.

The criteria for diagnosis of Diabetes Mellitus includes a fasting blood sugar level of $>126 \mathrm{mg} / \mathrm{dl}$ (OR) - two hours plasma glucose level of $>200 \mathrm{mg} / \mathrm{dl}$ after a glucose challenge (OR) - Symptoms of Diabetes Mellitus (Polyuria, Polydypsia, Weight loss) + Random Blood Sugar levels of $>200 \mathrm{mg} / \mathrm{dl}$.

Diabetes is also one of the diseases which directly affect aging systems. Conversely, both the incidence and the prevalence of diabetes mellitus increase with aging. It is a disease associated with a chronic inflammatory state in the body.

Although most standard textbooks do not point to an agerelated difference in platelet count, yet some studies have observed a small, but significant decrease in platelet count of the elderly when compared to the younger age groups. However, in Diabetic individuals, this decline in platelet count is not seen, instead a rise in platelet count or thrombocytosis has been observed.

Platelets

Platelets, also called thrombocytes, are a component of blood whose function (along with the coagulation factors) is to react to bleeding from blood vessel injury by clumping, thereby initiating a blood clot.Platelets have no cell nucleus: they are fragments of cytoplasm that are 
derived from the megakaryocytes of the bone marrow, and then enter the circulation. Platelets are lens-shaped structures, $2-3 \mu \mathrm{m}$ in diameter.

\section{Thrombopoiesis:}

Production of Platelets from the bone marrow is called Thrombopoiesis. Pluripotent Hematopoietic stem cell (HSC) converted into Megakaryocyte-Colony Forming Unit. This committed cell line develops into platelets after passing through 3 stages, which include:

1.MEGAKARYOBLAST- Earliest recognizable precursor cell, large size, has a large oval nucleus with several nucleoli.

\section{PROMEGAKARYOCYTE- Formed from Megakaryoblast which undergoes ENDOREDUPLICATION of nuclear chromatin.}

3. MEGAKARYOCYTE - Promegakaryocyte matures into megakaryocyte. Single Multilobed (4-16 lobes) nucleus which contains coarsely clumped chromatin. Cell margin is irregular with many pseudopodia. Platelets are formed from detached pseudopodia containing cytoplasm and other cytoplasmic contents like granules and clotting factors etc. About 4000 platelets arise from each megakaryocyte. Formation takes about 10 days and is regulated by Colony stimulating factors and a circulating protein hormone (TPO) THROMBOPOEITIN which increases platelet production. TPO is produced by the liver and kidney . Normal platelet count is between 150000 to 300000 cells per microlitre.
It has been observed that diabetic individuals have a higher platelet count when compared to non-diabetic individuals , which is also a contributory factor in the pathogenesis of CVD .

\section{Aims and Objectives of the Study:}

To compare the platelet count of elderly diabetics with nondiabetics.

\section{Materials and Methods:}

1. STUDY GROUP: 100 elderly (65-75 years) Type 2 Diabetics, 67 males and 33 females, of $>5$ years duration.

2. CONTROL GROUP: 100 age matched non-diabetics, 60 males and 40 females.

Informed Consent was taken from both groups.

\section{HAEMATOLOGICAL PARAMETERS ASSESSED:}

1. Platelet count - using Automated Analyzer

2. Random Blood Sugar - Glucose Oxidase - Peroxidase (GOD/POD) method.

\section{Inclusion and Exclusion Criteria: Inclusion Criteria:}

Subjects between 65-75 years with Type 2 Diabetes Mellitus for $>5$ years as study group.

Non-diabetic age matched subjects as control group.

\section{Exclusion Criteria:}

Subjects having any other chronic diseases and/or taking drugs for the same.

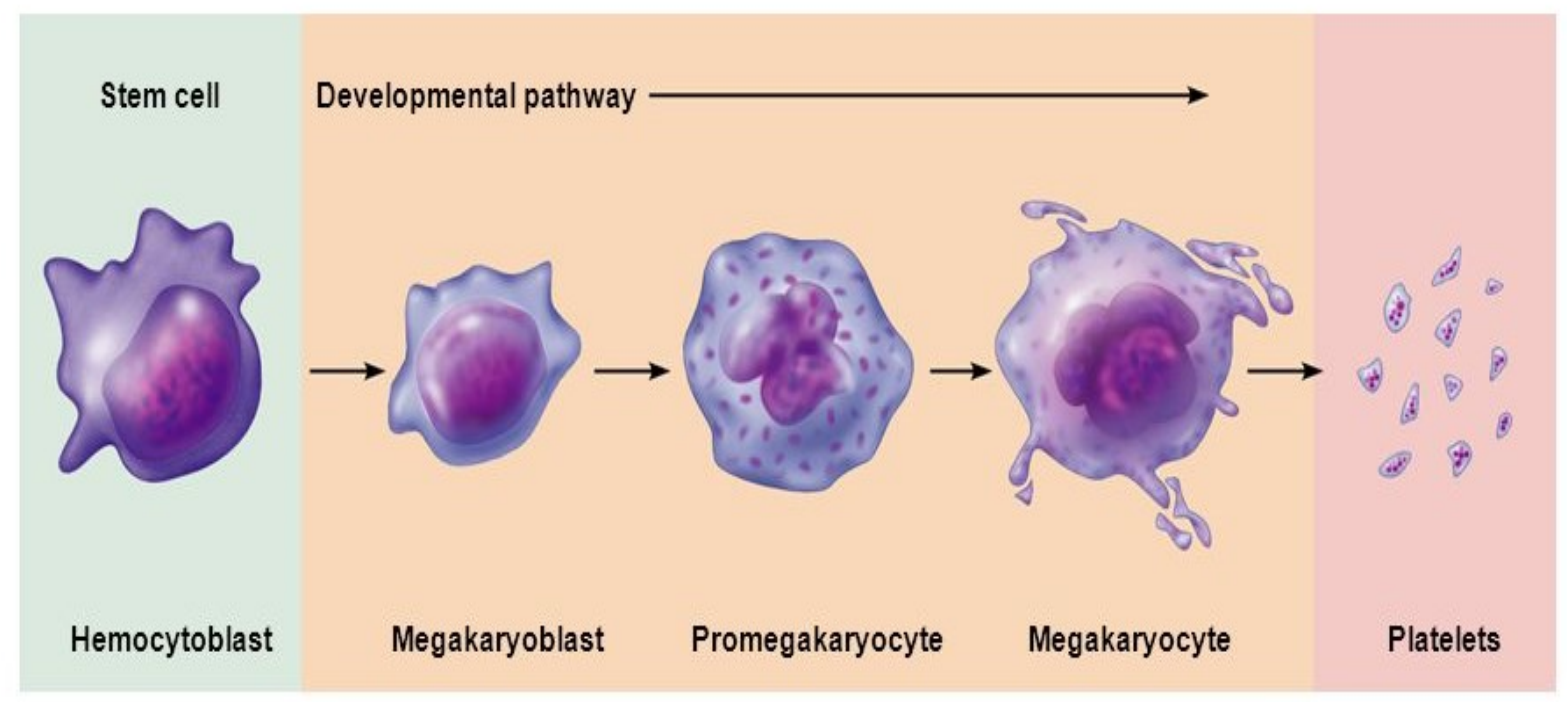



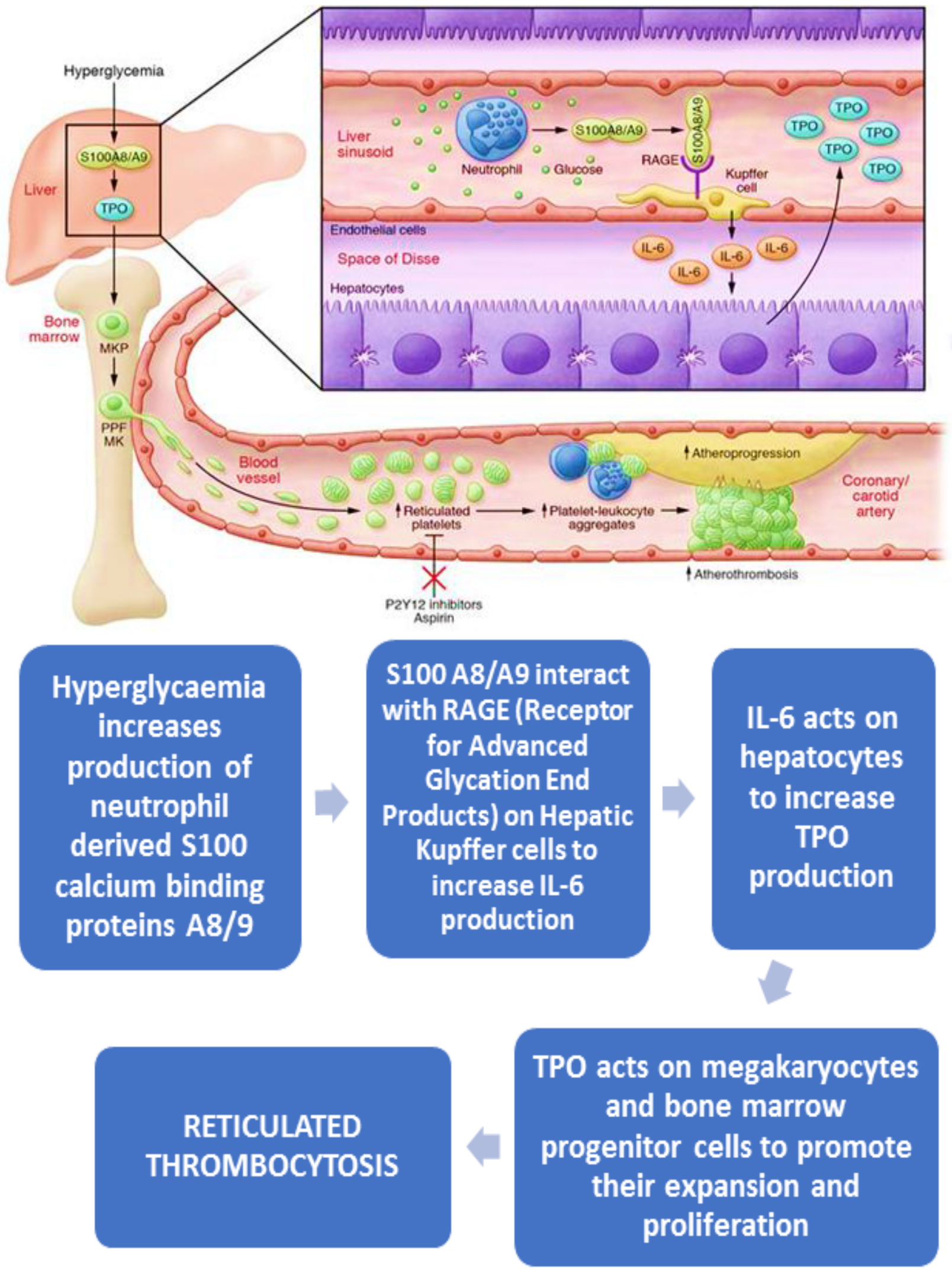


\section{Discussion:}

This study intended to compare the platelet count of diabetics and non-diabetic elderly individuals. RBS was done in both groups to rule out hyperglycaemia in control group. All the diabetic subjects were on oral medication only and were prescribed Metformin with or without Glimepiride by their respective Physicians. Metformin doesn't have any effect on platelet count. Side effects of Glimepiride include agranulocytosis and aplasticanaemia, though hypoglycaemia is more common. But as the cell counts of all individuals in the study group have been observed to be within normal range, it can be safely assumed that the drug didn't interfere with the platelet count.

Both Platelet count and Random Blood sugar were observed to be signicantly higher in the elderly diabetic compared to nondiabetics.

One of the possible explanations could be the effect of $4,6 \mathrm{H}$ yperglycaemia on the increased production of IL-6.

Studies have shown that Hyperglycaemia leads to increased production of neutrophil derived S100 Calcium binding proteins A8/A9. S100 is a multigenic family of nonubiquitous Calcium modulated proteins of the $\mathrm{EF}$ - hand type family. They are implicated in intracellular and extracellular regulatory activities. This family of proteins act as Calcium sensor proteins which participate in Calcium signal transduction by interacting with target proteins and hence modify the target's activities. They also mediate inflammatory responses and recruit inflammatory cells to sites of tissue damage.

S100 proteins act as ligands for RAGE - RECEPTOR for Advanced Glycation End Products (AGE). AGE are formed due to non-enzymatic glycosylation of intra and extracellular proteins which occur as a result of interaction of glucose with amino groups on proteins. AGEs are known to cross-link proteins such as collagen, Extracellular matrix proteins, accelerate atherosclerosis and induce endothelial dysfunction. Their serum levels correlate with degree of glycaemia.

RAGE is seen in a variety of immune and inflammatory cells, one of them being hepatic Kupffer cells. When S100 A8/A9 bind to the AGE receptor on the Kupffer cells, there occurs enhanced production of Interleukin-6 (IL-6). Interleukin-6, an inflammatory cytokine acts on Hepatocytes to increase production of Thrombopoietin.

Thrombopoietin increases platelet count by acting on bone marrow progenitor cells resulting in their expansion and proliferation. It also interacts with its cognate receptor cMPL on megakaryocytes. Ultimately reticulated thrombocytosis is seen. Reticulated platelets refers to the younger and more active platelets. It has also been observed in studies that when antiplatelet therapy is prescribed to diabetic subjects with uncontrolled blood sugar levels, its usually less effective as reticulated platelets show some resistance to antiplatelet drugs. Significant role of reticulated platelets have been implicated in promoting atherosclerotic plaque formation in some studies.

\section{Conclusion:}

Ageing leads to decline in functionality of the body. Added to this discomfort, there are the associated morbidities of chronic diseases, of which the most notorious one could probably be Diabetes Mellitus. Incidence of Diabetes increases with advancing age.

This study compared the platelet count of elderly diabetics with elderly non-diabetics. RBS was taken to ensure that non-diabetics had normoglycaemia as well to document the blood sugar levels in both groups. Hyperglycaemia, was seen in the diabetic group, which lead to significant rise in platelet count in the elderly diabetic, compared to the elderly non-diabetic. This occurred due to increased production of S100 proteins A8/A9 which are ligands for RAGE. Their interaction caused increased production of IL-6 from Hepatic Kupffer cells which caused enhanced release of Thrombopoietin from Hepatocytes. Thrombopoietin is responsible for Reticulated Thrombocytosis, which in turn is associated with complications like thrombosis, atherogenesis, CVD.

Recent studies have shown that if any of the steps right from production of S100 proteins till Thrombopoietin production is halted, thrombocytosis is not likely to occur. Eg: Addition of Dapagliozin in treatment of Diabetes resulted in controlled blood sugar levels as well as absence of reticulated thrombocytosis.

Control of blood sugar levels will prevent rise of platelet count. Additionally, regular monitoring of haematological parameters like cell counts could forewarn about the development of CVD in the elderly diabetic subject.

\section{References:}

1. WHO - Health statistics and information system; Proposed working denition of an older person in Africa for the MDS project.

2. WHO - Ageism and life course - Frequently asked questions.

3. WHO - Ageing and Life course - Infographics and fact sheet.

4. Harrisons Principles of Internal Medicine 17th ed, chap 9; Geriatric Medicine, p5354, 77.

5. Harrisons Principles of Internal Medicine 17th ed, Chap 338- Diabetes Mellitus, p2275-77, 2286

6. Harrison's Principles of Internal Medicine 19th ed, chap 11, clinical problems of ageing, p81-82.

7. Kraakman et.al, Neutrophil-derived S100 calcium binding proteins A8/A9 promote reticulated 
thrombocytosis and atherogenesis in diabetes; J Clin Invest. 2017;127(6:2133-2147)

8. SeemaAbhijeetKaveeshwar, Jon Cornwall, The current state of diabetes mellitus in India, Australas Med J; 2014; 7(1): 45-48.

9. Carlo L. Balduini and PartiziaNoris, Platelet Count and Aging, Haematologica. 2014 Jun; 99 (6): 953-955.

10. Akinsegun et.al, Mean Platelet volume and platelet counts in Type 2 Diabetes Mellitus on treatment and non-diabetic controls in Lagos; Nigeria, Pan Afr Med J.2014; 18:42.

11. http://www.netdoctor.co.uk/conditions/heart-andblood/a1177/ thrombocytopenia- reduced-plateletcount/

12. Ganongs Review of Medical Physiology, 24th ed, Chap 3, Immunity, Infection and Inammation, p78,80.

13. Guyton and Hall Textbook of Medical Physiology, 13th ed, Unit VI, Chap 37, Haemostasis and Blood Coagulation, p483.

14. Debra Prow, MD, SarojVadhan-raj, MD, Thrombopoietin: Biology and Potential Clinical Applications, ONCOLOGY 12(11):1597-1608, 1998

15. MarkkuLaakso, Cardiovascular Disease in Type 2 Diabetes from Population to Man to Mechanisms, The Kelly West Award Lecture 2008, Diabetes Care 2010 Feb; 33 (2): 442-449.
16. Goodman and Gillman's The Pharmacological Basis of Therapeutics, 10th ed, Chap 61, Insulin, Oral Hypoglycaemic agents, pharmacology of the Endocrine Pancreas, p1701-06.

17. Roth J et al, Phagocyte specic S100 proteins: a novel group of proinammatory molecules; Trends Immunol. 2003 Apr;24(4):155-8.

18. Donato R; Intracellular and extracellular roles of S100 proteins, Microsc Res Tech, 2003 Apr 15; 60 (6): 54051.

19. Donato R, RAGE: a single receptor for several ligands and different cellular responses: the case of certain S100 proteins; Curr Mol Med. 2007 Dec;7(8): 711-24.

20. Foell D et al, S100 proteins expressed in phagocytes: a novel group of damageassociated molecular pattern molecules; J LeukocBiol, 2007 Jan; 81 (1): 28-37. Epub 2006 Aug 30.

21. Kierdorf K, Fritz G, RAGE regulation and signaling in inammation and beyond, J Leukoc Biol. $2013 \mathrm{Jul}$; 94(1): 55-68.

22. Guthikonda $\mathrm{S}$ et al, Role of reticulated platelets and platelet size heterogeneity on platelet activity after dual antiplatelet therapy with aspirin and clopidogrel in patients with stable coronary artery disease, J Am CollCardiol. 2008 Aug 26; 52 (9): 743-9. 